OPEN ACCESS

Edited by:

Daniel John Blackwood, National University of

Singapore, Singapore

Reviewed by:

Changdong Gu,

Zhejiang University, China

Shaojun Yuan,

Sichuan University, China

*Correspondence:

Xianbo Shi

xbshi@imr.ac.cn

Ke Yang

kyang@imr.ac.cn

Specialty section:

This article was submitted to

Environmental Materials,

a section of the journal

Frontiers in Materials

Received: 06 September 2019

Accepted: 20 March 2020

Published: 20 May 2020

Citation:

Shi X, Yang $K$, Yan $M$, Yan W and Shan Y (2020) Study on

Microbiologically Influenced Corrosion

Resistance of Stainless Steels With

Weld Seams. Front. Mater. 7:83.

doi: 10.3389/fmats.2020.00083

\section{Study on Microbiologically Influenced Corrosion Resistance of Stainless Steels With Weld Seams}

\author{
Xianbo Shi ${ }^{1,2 *}$ Ke Yang ${ }^{1 *}$, Maocheng Yan ${ }^{1}$, Wei Yan ${ }^{1,2}$ and Yiyin Shan ${ }^{1,2}$ \\ ${ }^{1}$ Institute of Metal Research, Chinese Academy of Sciences, Shenyang, China, ${ }^{2}$ Key Laboratory of Nuclear Materials and \\ Safety Assessment, Chinese Academy of Sciences, Shenyang, China
}

Stainless steels are widely used in various industries due to their desirable combination of mechanical properties and corrosion resistance. However, corrosion of stainless steels was reported seriously on the weld seam areas, and it is not exceptive for microbiologically influenced corrosion (MIC). In the present study, MIC resistance of two austenitic stainless steels (A1, A2 for short) and a duplex stainless steel (D1 for short) with weld seams were comparatively studied by measurement of average and maximum pit depths and electrochemical tests. Experimental results showed that the pit depth on the weld seam was much deeper than that on the base metal for all the stainless steels. The variations in linear polarization resistance $\left(R_{\mathrm{LPR}}\right)$ values on base metal and weld seam showed that weld seam could promote MIC. Thus, the study indicated that the weld seam accelerated the MIC. In addition, A1 steel with higher $\mathrm{Cu}$ content showed the best MIC resistance, followed by A2 steel with lower Cu content, and D1 steel without $\mathrm{Cu}$ addition exhibited the worst resistance to $\mathrm{MIC}$, indicating that $\mathrm{Cu}$ addition in stainless steels is speculated to be beneficial to the MIC resistance. The mechanisms of $\mathrm{Cu}$ improving the MIC resistance in the stainless steels were discussed.

Keywords: microbiologically influenced corrosion, austenitic stainless steel, duplex stainless steel, weld seam, base metal, pitting corrosion

\section{INTRODUCTION}

A type of corrosion that can be very harmful to almost all the engineering materials is what is called microbiologically influenced corrosion (MIC). MIC is the term used for the phenomenon in which corrosion is initiated and/or accelerated by the activities of microorganisms (Javaherdashti, 2008). It is an electrochemical process, which occurs under the combination of energy source, carbon source, electron donor, electron acceptor, and water (Javaherdashti, 2008). MIC is widespread in every corner of national economic constructions, and it can occur in various environments such as soil, fresh water, seawater, power generation, marine engineering, and oil field (Javaherdashti, 2008), for example, cooling water circulation system of power plant, ship system, oil exploitation, storage and transportation system, sewage treatment pipeline, drinking water pipeline, locomotive fuel storage tank, and so on, where there are different degrees of MIC attacks. MIC is mainly a local corrosion (pitting corrosion), and its occurrence and development are unpredictable in time and space.

According to the statistics, MIC is believed to account for $20 \%$ of all the corrosion damages (Alabbas et al., 2013). It was reported that $75 \%$ corrosion of oil well pipes and $50 \%$ failures of buried pipelines are caused by MIC in the United States (Shi et al., 2019; Yang et al., 2020). In 2002, 
a survey of the United States showed that corrosion losses accounted for $3.1 \%$ of gross domestic product (GDP), of which MIC accounted for $~ 20 \%$, and the annual loss caused by MIC was about US\$3-5 billion (Shi et al., 2019; Yang et al., 2020). The direct cost of MIC is estimated to exceed RMB 50 billion per year in China (Shi et al., 2019; Yang et al., 2020). It should be emphasized that these data are out of date and do not reflect the real losses today. Nevertheless, the loss caused by MIC is great, and it is very difficult to mitigate MIC. It is therefore important to improve our understanding of MIC and to take measures to mitigate occurrence of MIC.

Stainless steels are widely used in various industries due to their desirable combination of mechanical properties and corrosion resistance. The corrosion resistance of stainless steels is mainly determined by the addition of corrosion resistant elements such as $\mathrm{Cr}$ and Mo and control of microstructure. Austenitic stainless steel (ASS) and duplex stainless steel (DSS) contain high levels of $\mathrm{Cr}, \mathrm{Mo}$, and $\mathrm{Ni}$ resulting in excellent corrosion resistance and good pitting corrosion resistance due to their high pitting resistance equivalent number (PREN). However, no matter if it is austenitic or duplex stainless steel, the localized pitting corrosion caused by microorganisms is still inevitable (Huttunen-Saarivirta et al., 2012; Tribollet, 2012; Liu, 2014; Li et al., 2016; Zhou et al., 2018; Dong et al., 2020; Yu et al., 2020). Lekbach et al. (2019) reported that the Pseudomonas aeruginosa biofilm could accelerate the corrosion of 304L ASS. $\mathrm{Xu}$ et al. (2017) found that $P$. aeruginosa significantly reduced the corrosion resistance of 2205 DSS, and the largest pit on 2205 DSS caused by adhesion of $P$. aeruginosa reached to $14.0 \mu \mathrm{m}$. Liu et al. (2018a) believed that Chlorella vulgaris could promote the pitting corrosion of $316 \mathrm{~L}$ ASS. The pitting corrosion was observed in the presence of C. vulgaris with pit depth of $20 \mu \mathrm{m}$ formed on the surface after 21 days of incubation.

Literatures about MIC of stainless steels were mainly focused on the base metals. As a structural material, welding of stainless steel is necessary for engineering applications. The welding area deserves special attention due to its role of reducing the corrosion resistance. However, there were few studies concerning the effect of weld seam on the MIC behavior of stainless steel (Sreekumari et al., 2001; George et al., 2003). It is also worth noting that the published work only evaluated the MIC of weld seam with filler metal addition (Sreekumari et al., 2001). Thus, there is a research gap for investigating MIC on the weld seam without filler metal addition. The present study aimed to evaluate the MIC behavior of three stainless steels with weld seams (electric resistance welding, no filler metal addition) and the base metal microstructures simultaneously, which was seldom reported previously. This is the novelty of this paper. In addition, the MIC resistance of three stainless steels was also analyzed from the metallurgical features. Especially, the mechanisms of $\mathrm{Cu}$ improving the $\mathrm{MIC}$ resistance in the stainless steels were discussed.

\section{EXPERIMENTAL PROCEDURES}

\section{Materials}

Three different commercial stainless steels, including two austenitic stainless steels (referred as A1 and A2 steels, respectively) and a duplex stainless steel (referred as D1 steel) were used in this study. The specific chemical compositions of these steels are listed in Table 1. All the experimental steels were in as-received condition (annealed).

For electrochemical measurements, rectangular flat coupons with dimension of $10 \mathrm{~mm} \times 10 \mathrm{~mm} \times 5 \mathrm{~mm}$ were employed. Two different coupons (i) coupons with weld seam generated by electric resistance welding (ERW) without addition of filler metal and (ii) coupons with only base metal, were used. The coupons were first embedded in an epoxy resin, leaving an exposed area of $100 \mathrm{~mm}^{2}$. For electrical connection, a copper wire was soldered at the rear of the coupons. The coupons were ground to 1,000\# by a series of sand papers, cleaned in acetone and alcohol, and finally dried by a hair drier. The same coupons for surface morphology analyses were also treated by the same method as above. All the coupons were sterilized under ultraviolet for $30 \mathrm{~min}$ before experiment.

\section{Microstructure Observation}

Microstructure characterization of three stainless steels including base metal and weld seam was performed. Rectangular flat coupons with an area of $1 \mathrm{~cm}^{2}$ were mechanically ground to 2,000\# by a series of sand papers, polished, and then etched in a $5 \mathrm{~g} \mathrm{FeCl}_{3}+50 \mathrm{ml} \mathrm{HCl}+100 \mathrm{ml}$ distilled water mixed solution. The microstructure characteristic was observed under a Zeiss LSM700 optical microscope.

\section{Bacterial Medium}

MIC test was conducted in the API RP-38 medium containing sulfate-reducing bacteria (SRB). The same SRB strain was used as described in our previous papers (Shi et al., 2017a,b, 2018). The strain was not identified in the present study because the corrosion mechanism of this strain has been discussed previously (Shi et al., 2018). They were anaerobically cultured in the API RP-38 medium with the following compositions: $0.2 \mathrm{~g} / \mathrm{L}$ $\mathrm{MgSO}_{4} \bullet 7 \mathrm{H}_{2} \mathrm{O}, 0.5 \mathrm{~g} / \mathrm{L} \mathrm{KH}_{2} \mathrm{PO}_{4}, 10.0 \mathrm{~g} / \mathrm{L} \mathrm{NaCl}, 1.0 \mathrm{~g} / \mathrm{L}$ ascorbic acid, $4.0 \mathrm{~g} / \mathrm{L}$ sodium lactate, $1.0 \mathrm{~g} / \mathrm{L}$ yeast extract, and $0.02 \mathrm{~g} / \mathrm{L}$ $\mathrm{Fe}\left(\mathrm{NH}_{4}\right)_{2}\left(\mathrm{SO}_{4}\right)_{2}$. The $\mathrm{pH}$ of the medium was adjusted to 7.1 by $1 \mathrm{~mol} / \mathrm{L} \mathrm{NaOH}$. Prior to the test, the API RP-38 medium was sterilized in an autoclave at $121^{\circ} \mathrm{C}$ for $20 \mathrm{~min}$. The SRB were activated for $12 \mathrm{~h}$ at $37^{\circ} \mathrm{C}$ before use.

\section{Electrochemical Measurement}

The electrochemical measurement was performed in a sealed glass jar with volume of $1,000 \mathrm{ml}$. Before measurement, $950 \mathrm{ml}$ sterile API RP-38 medium was bubbled with $\mathrm{N}_{2}$ for 4 h to remove $\mathrm{O}_{2}$, and then, $50 \mathrm{ml} \mathrm{SRB}$-inoculated medium was injected into the jar by a syringe. Electrochemical measurement was conducted using a Gamry 600 electrochemical system in a conventional three-electrode electrochemical cell, consisting of a test coupon as working electrode, a Pt mesh as counter electrode, and a saturated calomel electrode (SCE) as reference electrode. Open circuit potential values of the system were monitored with immersion time. Linear polarization resistance $\left(R_{\mathrm{LPR}}\right)$ was recorded at a scan rate of $0.166 \mathrm{mV} / \mathrm{s}$ in the range of $\pm 10 \mathrm{mV}$ vs. open circuit potential, which was repeated three times. The total test lasted for 25 days at a constant temperature of $37^{\circ} \mathrm{C}$. 
TABLE 1 | Chemical compositions of experimental steels (wt.\%).

\begin{tabular}{|c|c|c|c|c|c|c|c|c|c|c|c|}
\hline Steels & C & Si & Mn & $\mathbf{P}$ & $\mathbf{S}$ & $\mathrm{Cu}$ & $\mathrm{Ni}$ & $\mathrm{Cr}$ & Mo & $\mathbf{N}$ & $\mathrm{Fe}$ \\
\hline $\mathrm{A} 1$ & 0.075 & 0.50 & 6.64 & 0.049 & 0.001 & 1.74 & 1.33 & 14.02 & 0.03 & 0.24 & Bal. \\
\hline $\mathrm{A} 2$ & 0.087 & 0.42 & 9.96 & 0.041 & 0.002 & 0.82 & 1.33 & 14.02 & 0.03 & 0.15 & Bal. \\
\hline D1 & 0.023 & 0.51 & 1.14 & 0.030 & 0.002 & - & 5.89 & 23.22 & 3.10 & 0.17 & Bal. \\
\hline
\end{tabular}
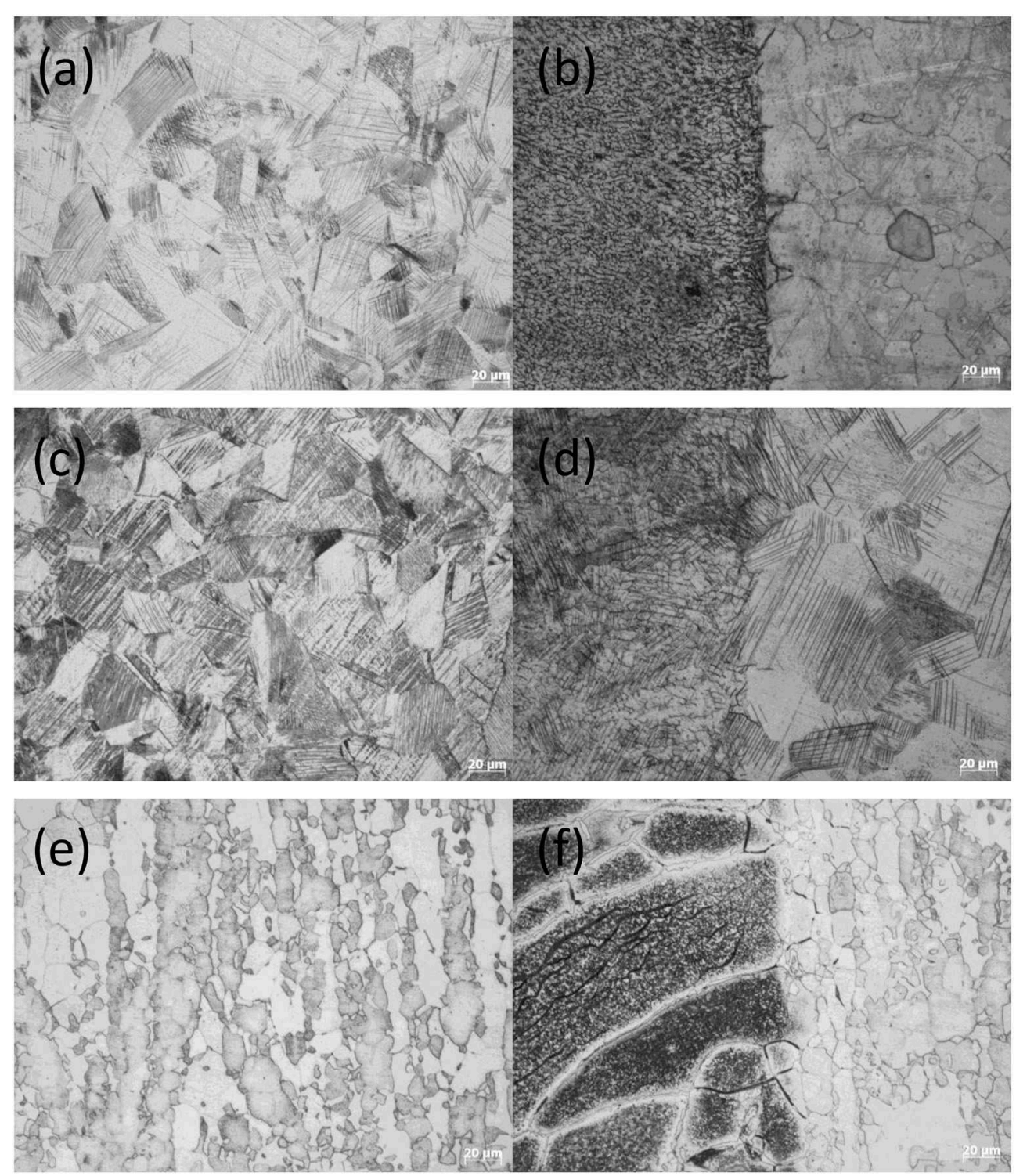

FIGURE 1 | Optical images of three stainless steels showing microstructures of base metal and weld seam: (a) A1 base metal, (b) A1 weld seam, (c) A2 base metal, (d) A2 weld seam, (e) D1 base metal, and (f) D1 weld seam.

\section{Surface Analysis}

After the test, the coupons were washed with PBS solution three times and immersed into $5 \%$ glutaraldehyde for $1 \mathrm{~h}$ to fix the biofilm. They were subsequently dehydrated with a graded series of ethanol (50, 75, and 100\%) before drying in cold air. The surface morphologies and pit depths were analyzed using a scanning electron microscope (SEM, MIRA3 TESCAN) and a confocal laser scanning microscope (CLSM, Zeiss LSM700), respectively. The largest pit depth and the average pit depth were obtained by measurements taken at 30 different locations for each coupon. 


\section{RESULTS AND DISCUSSION}

\section{Microstructures}

The microstructure and grain size of stainless steels are considered to play an important role in the MIC process (Ibars et al., 1992). These two factors are compared in the present study. Figure 1 shows the microstructures of three stainless steels in base metal and weld seam areas. Obviously, austenitic stainless steels (A1 and A2) are characterized by typical austenitic microstructure, showing similar equiaxed austenite grains. The grains are in the size range of $30-40 \mu \mathrm{m}$ for the A1 steel and $20-30 \mu \mathrm{m}$ for the A2 steel. The duplex stainless steel (D1) is composed of ferrite (gray) and austenite (white) microstructures. The grain size is not uniform, varying in the range of $10-30 \mu \mathrm{m}$. Compared with base metal, the weld seam microstructure is different. For A1 and A2 steels, the grains in weld seam areas are very small, with high density of grain boundaries. The grain size of D1 steel in weld seam area is much larger than that in base metal. However, the grain boundaries between ferrite and austenite become wider, and a large number of fine subgrain boundaries appear within grains.

\section{Characteristic of SRB Growth}

The number of SRB was determined by the three-tube multiple most probable number (MPN) method according to the American Society for Testing and Materials (ASTM) Standard D4412-84. The growth curve of planktonic SRB in the API RP38 medium is presented in Figure 2. After a lag phase in the first day, the number of SRB entered a logarithmic growth phase in the next 4 days, where the planktonic SRB number reached a peak number of $1.6 \times 10^{7} \mathrm{cfu} / \mathrm{ml}$ on day 5 . Then, it began to decrease gradually, reaching $1.3 \times 10^{5} \mathrm{cfu} / \mathrm{ml}$ on day 10 and $5.0 \times 10^{2} \mathrm{cfu} / \mathrm{ml}$ at the end of the test. As we know, SRB are special bacteria that gain their biochemical energy for growth by oxidizing certain organic compounds or hydrogen $\left(\mathrm{H}_{2}\right)$ with sulfate (or other sulfur compounds such as sulfite, thiosulfate, or sulfur) as terminal electron acceptors and reducing these compounds to sulfides $\left(\mathrm{H}_{2} \mathrm{~S}\right.$ and $\left.\mathrm{HS}^{-}\right)$(Beech, 2003). Sulfides produced by SRB also play an important role in pitting corrosion. Based on the work of Yuan et al. (2013), it can be speculated that the sulfide concentration should be same with the trend of SRB growth process.

\section{Surface Morphology and Pit Depth}

In general, when exposed to SRB, the coupon surface would be covered by a thick layer containing the biofilm/corrosion product (Shi et al., 2018; Liu et al., 2019). However, it is inconceivable that the biofilm/corrosion product on the coupons is slim, and only a few of bacteria (shown as red arrows in Figure 4) and a large of original scratches can be observed (Figure 4). It is possible that SRB did not grow under the present experimental condition; however, it is not in conformity with the SRB growth curve shown in Figure 2. Another possibility is that A1 and A2 steels contain some amount of copper $(\mathrm{Cu}) . \mathrm{Cu}$ is an important alloying element with antimicrobial effect in steels (Liu et al., 2018c, 2019; Shi et al., 2018; Xu et al., 2018). Cu ions released from $\mathrm{Cu}$-rich phase in the steel can kill bacteria and inhibit the

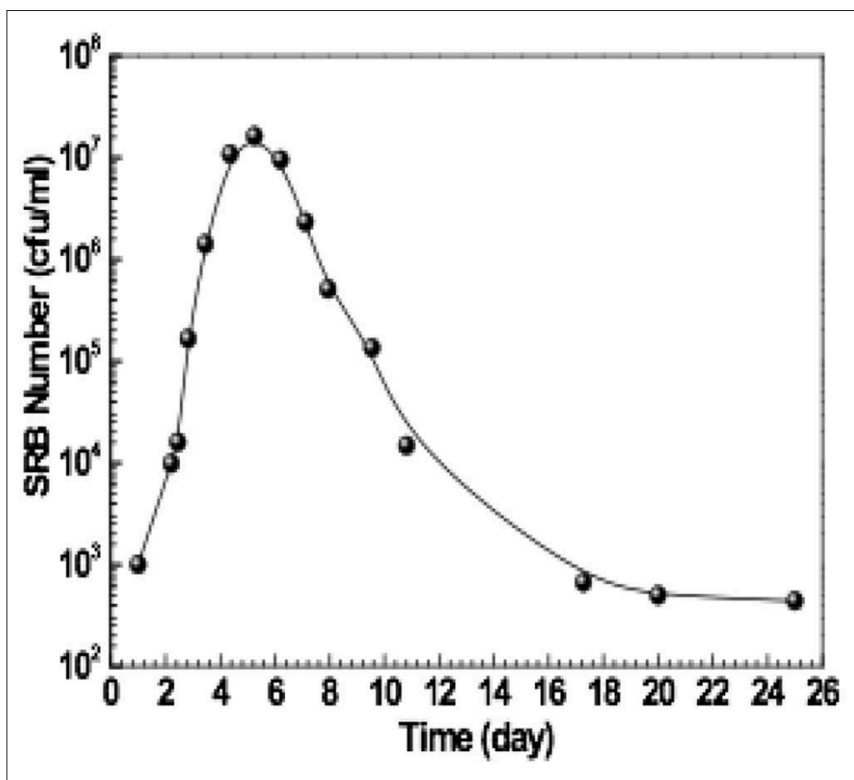

FIGURE 2 | Growth curve of sulfate-reducing bacteria (SRB) in the API RP-38 medium.

formation of bacterial biofilm (Nan et al., 2012; Xia et al., 2015; Shi et al., 2018; Xu et al., 2018). However, it is not true for the $\mathrm{D} 1$ steel without $\mathrm{Cu}$ addition. Thus, the only possibility is that the biofilm is not fixed completely and fell off during drying in cold air.

Figure 3 shows parts of biofilm/corrosion products that did not fall off, which were observed on the surface of A2 coupon. Energy dispersive spectrum (EDS) analysis showed that those biofilm/corrosion products contained $\mathrm{C}, \mathrm{O}, \mathrm{S}$, and $\mathrm{P}$, which are the typical metabolites of SRB (Wu et al., 2014). Besides, $\mathrm{Na}, \mathrm{Mg}$, $\mathrm{K}, \mathrm{Cl}$, and $\mathrm{Ca}$ were detected in the biofilm/corrosion products, which might come from the API RP-38 medium, and Fe, Cr, Si, $\mathrm{Mn}$ came from the steel matrix (Figure 3a). In contrast, only Fe, $\mathrm{Mn}, \mathrm{Cr}$, and Si but no S were detected on the surface outside the biofilm/corrosion products (Figure $3 \mathbf{b}$ ). Thus, it is reasonable believe that biofilm/corrosion products were formed during the experimental process, and MIC has occurred on the steels although thick biofilm/corrosion products were not observed.

Figure 4 shows the corrosion attacked surface morphologies of the three stainless steels. Some aggressive pits can be observed scattering on the surface of coupons (shown as red circles in Figure 4), and the original scratches are still clear. This fact proves that MIC has indeed occurred on the coupons of the three stainless steels although no obvious biofilm was found. From the locations of the pits, it can be found that there are always a few $\mathrm{SRB}$ colonies and their metabolites around the pits (shown as red arrows in Figure 4), and they are the same for both base metal and weld seam. Thus, it is confirmed that pitting corrosion caused by SRB occurred on both base metal and weld seam, and the pits were produced by SRB or its metabolism product instead of the culture medium (Li et al., 2009; Yuan and Pehkonen, 2009; Yuan et al., 2013; Dec et al., 2016). This can also be supported by a 

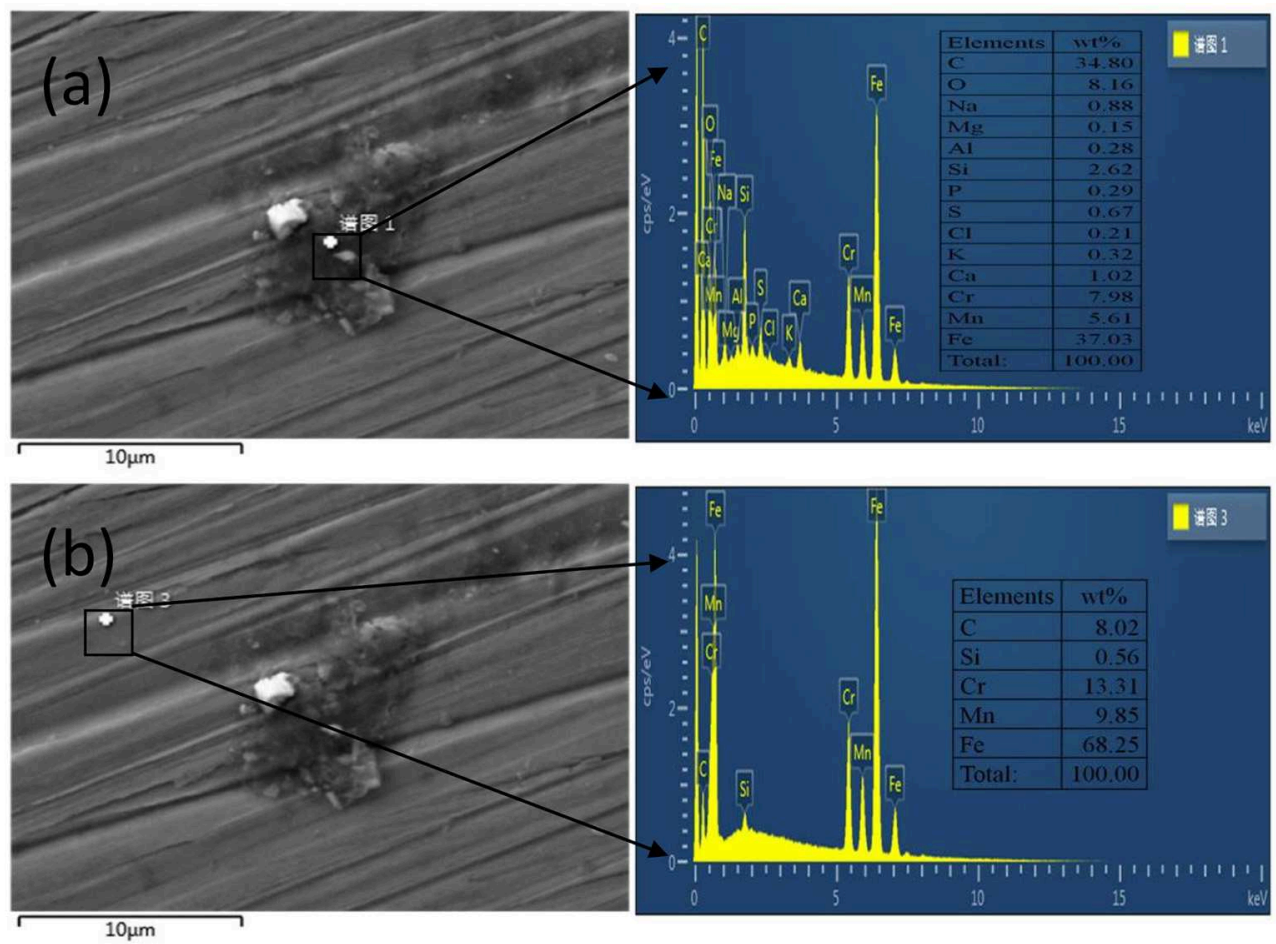

FIGURE 3 | Scanning electron microscopy (SEM) morphologies and energy-dispersive X-ray spectroscopy (EDS) analyses of corrosion products on the surface of A2 coupon exposed to sulfate-reducing bacteria (SRB) for 25 days. (a) Position of EDS analysis: biofilm/corrosion products, (b) Position of EDS analysis: matrix.

previous study that showed no pits appeared in the same medium without SRB (Shu et al., 2018).

MIC is associated with pitting that is the main cause of fast and unexpected failure of stainless steels. Thus, the MIC resistance index can be characterized by measurement of the pit depth. To compare the pitting corrosion resistance, 30 pits on both base metal and weld metal areas, respectively, with randomly locations were mapped by CLSM. It is worthy of noting that only the pits on the weld seam area were counted for the weld seam coupons. The pitting profiles imaged by CLSM (Figure 5) show that the deepest pits are $4.9,5.6$, and $7.4 \mu \mathrm{m}$ for $\mathrm{A} 1, \mathrm{~A} 2$, and D1 base metals, respectively. While the deepest pits on weld seam areas are 6.2, 10.4 , and $12.3 \mu \mathrm{m}$ for A1, A2, and D1, respectively. Obviously, the deepest pit on the weld seam is deeper than that on the base metal. Table 2 shows the statistical values of the pit depth of the three stainless steels on base metal and weld seam areas. The average pit depths of the base metal from total 30 pits are 3.1 $\pm 1.3,4.2 \pm 1.1$, and $4.6 \pm 2.2 \mu \mathrm{m}$ for A1, A2, and D1 steels, respectively. However, the average pit depths on weld seam areas are $4.1 \pm 1.9,6.0 \pm 3.2$, and $7.1 \pm 3.9 \mu \mathrm{m}$, respectively, obviously deeper than those on the base metals. Thus, the pitting corrosion on the weld seam areas caused by SRB should be more serious than that on the base metal, no matter the average pitting depth and the maximum pitting depth.

Weld seam is a special area for welded stainless steel, and the combination of physical and compositional changes brought by the welding process is believed to alter the material surface characteristics or the local microstructure change. In the present study, the filler metal was not added during the welding process, so the influence of composition change in the weld seam was ignored. However, the weld seam area had smaller grains compared with the base metal for A1 and A2 steels (Figure 1). Although the weld seam area of D1 steel seemed to have larger grains, a large number of fine subgrains could be observed within the grains. This means that weld seam area contributed to a longer grain boundary per unit area than the base metal. It has been proven that grain boundaries prefer to the bacterial attachment due to the elemental segregation and different energy distribution between the grain boundary and matrix, and this increased bacterial attachment resulted in more serious MIC (Sreekumari et al., 2001). Although it is different from the fact that there was no large amount of biofilm and/or bacteria (SRB) observed on the weld seam areas in the present study, weld seam accelerating MIC is confirmed again from the data of pit depth.

In addition, it can be found that the pitting corrosion resistance of the A1 steel is better than that of the A2 steel (Table 2). This can be explained from the following metallurgical features. First, it has been recognized that the microstructure and surface roughness play important roles in the MIC process (Ibars et al., 1992; George et al., 2003). In the present study, A1 and A2 steels showed same microstructures, and uniform grinders were also used, i.e., same surface roughness. Thus, the effects of microstructure and surface roughness on the MIC can be excluded. Second, studies have shown preferential bacterial 

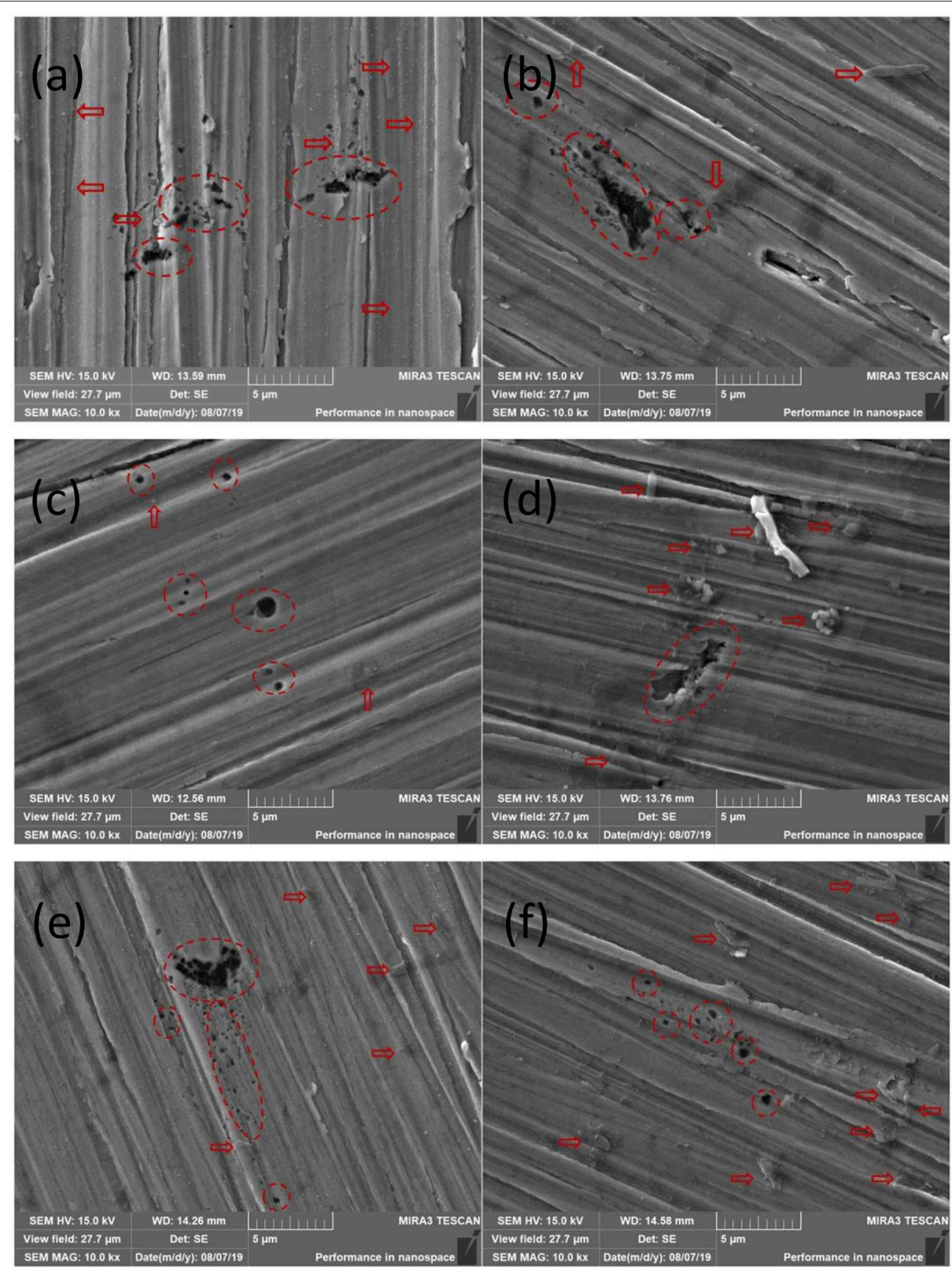

FIGURE 4 | Scanning electron microscopy (SEM) morphologies of pits on surfaces of coupons: (a) A1 base metal, (b) A1 weld seam, (c) A2 base metal, (d) A2 weld seam, (e) D1 base metal, and (f) D1 weld seam.

attachment on the grain boundaries in stainless steel (Sreekumari et al., 2001). This means that the smaller the grain size is, the worse the MIC resistance is. Since A2 steel has smaller grains than A1 steel, the pitting corrosion resistance of the A2 steel should be decreased compared with the A1 steel. Third, the A1 steel has higher copper $(\mathrm{Cu})$ content than the A2 steel. $\mathrm{Cu}$ and its alloys are known for their antimicrobial activity, and it makes $\mathrm{Cu}$ a desirable element in antibacterial metallic materials. Unexceptionally, $\mathrm{Cu}$ in steels still exhibits antibacterial performance (Nan et al., 2012; Xia et al., 2015; Shi et al., 2017a,b, 2018; Xu et al., 2018; Liu et al., 2019). However, the antibacterial effect of $\mathrm{Cu}$ is a very complicated and multifactorial process. On the one hand, $\mathrm{Cu}$ exhibits its antibacterial property in several different forms. Akhavan and Ghaderi (2010) reported that $\mathrm{CuO}$ nanoparticles immobilized by silica thin film heat treated at $300^{\circ} \mathrm{C}$ exhibited a strong antibacterial activity against Escherichia 

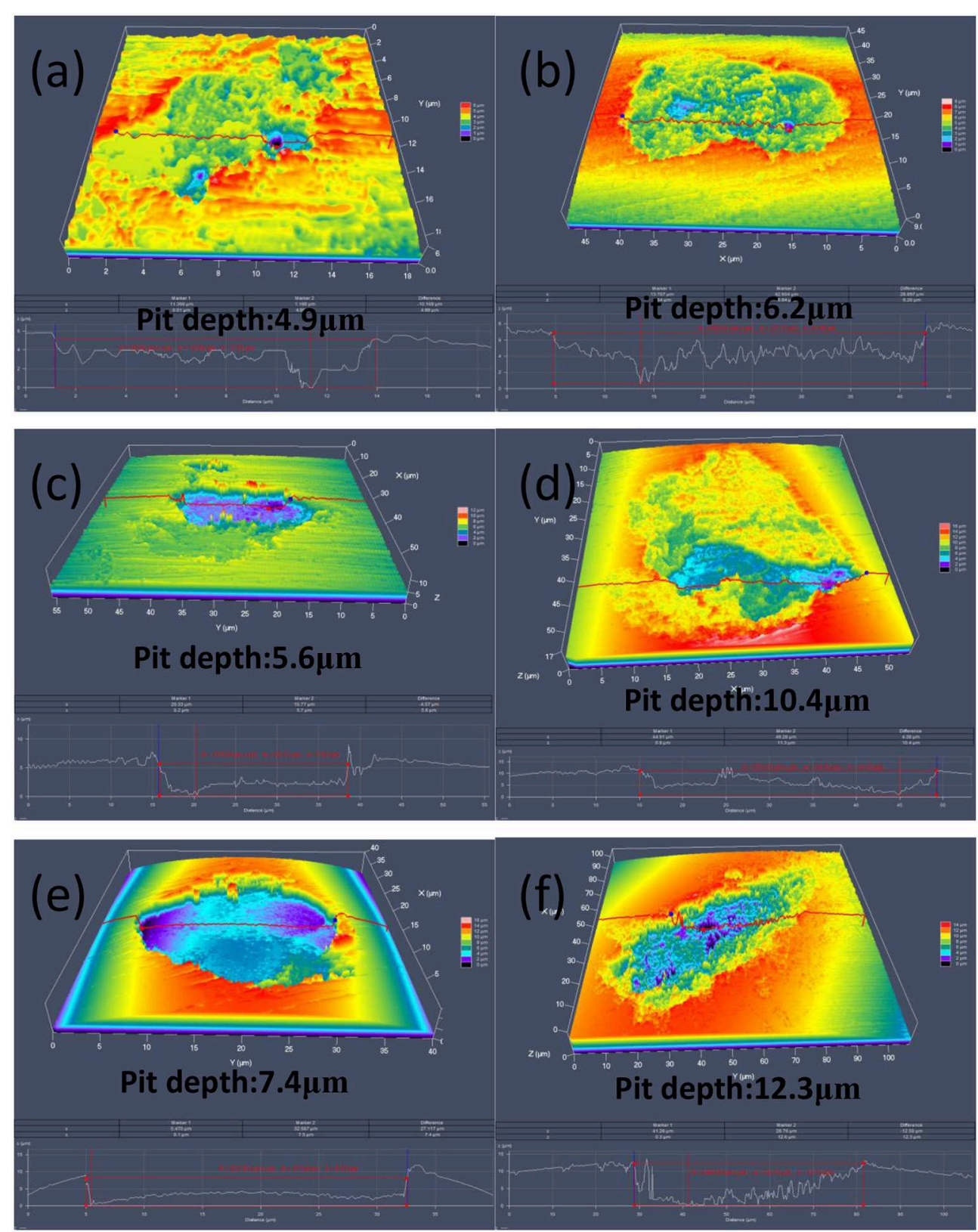

FIGURE 5 | Confocal laser scanning microscopy (CLSM) 3D images of pits on surfaces of coupons: (a) A1 base metal, (b) A1 weld seam, (c) A2 base metal, (d) A2 weld seam, (e) D1 base metal, and (f) D1 weld seam.

coli bacteria. Compared with $\mathrm{CdS}$ and SnS, CuS nanoparticles have the highest antimicrobial activity against Escherichia coli, Streptococcus aureus, Bacillus subtilis, and Candida albicans as well as Salmonella sp. (Mostafa et al., 2020). Ren et al. (2011) investigated the antibacterial efficacy of a $\mathrm{Cu}$-bearing stainless steel against E. coli and attributed its antibacterial property to the precipitation of $\varepsilon$-Cu phase. Xia et al. (2015) believed that inhibition of the biofilm was caused by $\mathrm{Cu}$ ions released from $\mathrm{Cu}$-rich phase in a 2205-Cu duplex stainless steel, leading to its effective mitigation of MIC by P. aeruginosa. Nan et al. (2012) also confirmed that the precipitation of $\mathrm{Cu}$-rich phase caused by saturated $\mathrm{Cu}$ in the austenitic stainless steel is a crucial factor to kill bacteria. On the other hand, $\mathrm{Cu}$ exhibits its antibacterial property by several different antibacterial mechanisms. An important one is $\mathrm{Cu}$ ions killing bacteria directly. Besides, the antibacterial effect of $\mathrm{Cu}$ is also attributed to its ability to accept and donate electrons as changing oxidation state between $\mathrm{Cu}^{+}$ and $\mathrm{Cu}^{2+}\left(\mathrm{O}^{\prime}\right.$ Gorman and Humphreys, 2012). This allows $\mathrm{Cu}$ to act as a catalyst for the generation of reactive oxygen species (ROS) that can cause oxidative damage to vital cell constituents 
TABLE 2 | Pit depths (measured from 30 pits for each) of the base metal and weld seam of three stainless steels after 25 days exposure in sulfate-reducing bacteria (SRB)-inoculated API RP-38 medium.

\begin{tabular}{|c|c|c|c|c|c|c|}
\hline \multirow[t]{2}{*}{ Steel } & \multicolumn{3}{|c|}{ Base metal } & \multicolumn{3}{|c|}{ Weld seam } \\
\hline & A1 & A2 & D1 & A1 & A2 & D1 \\
\hline Maximum pit depth $(\mu \mathrm{m})$ & 4.9 & 5.6 & 7.4 & 6.2 & 10.4 & 12.3 \\
\hline Average pit depth ( $\mu \mathrm{m})$ & $3.1 \pm 1.3$ & $4.2 \pm 1.1$ & $4.6 \pm 2.2$ & $4.1 \pm 1.9$ & $6.0 \pm 3.2$ & $7.1 \pm 3.9$ \\
\hline
\end{tabular}
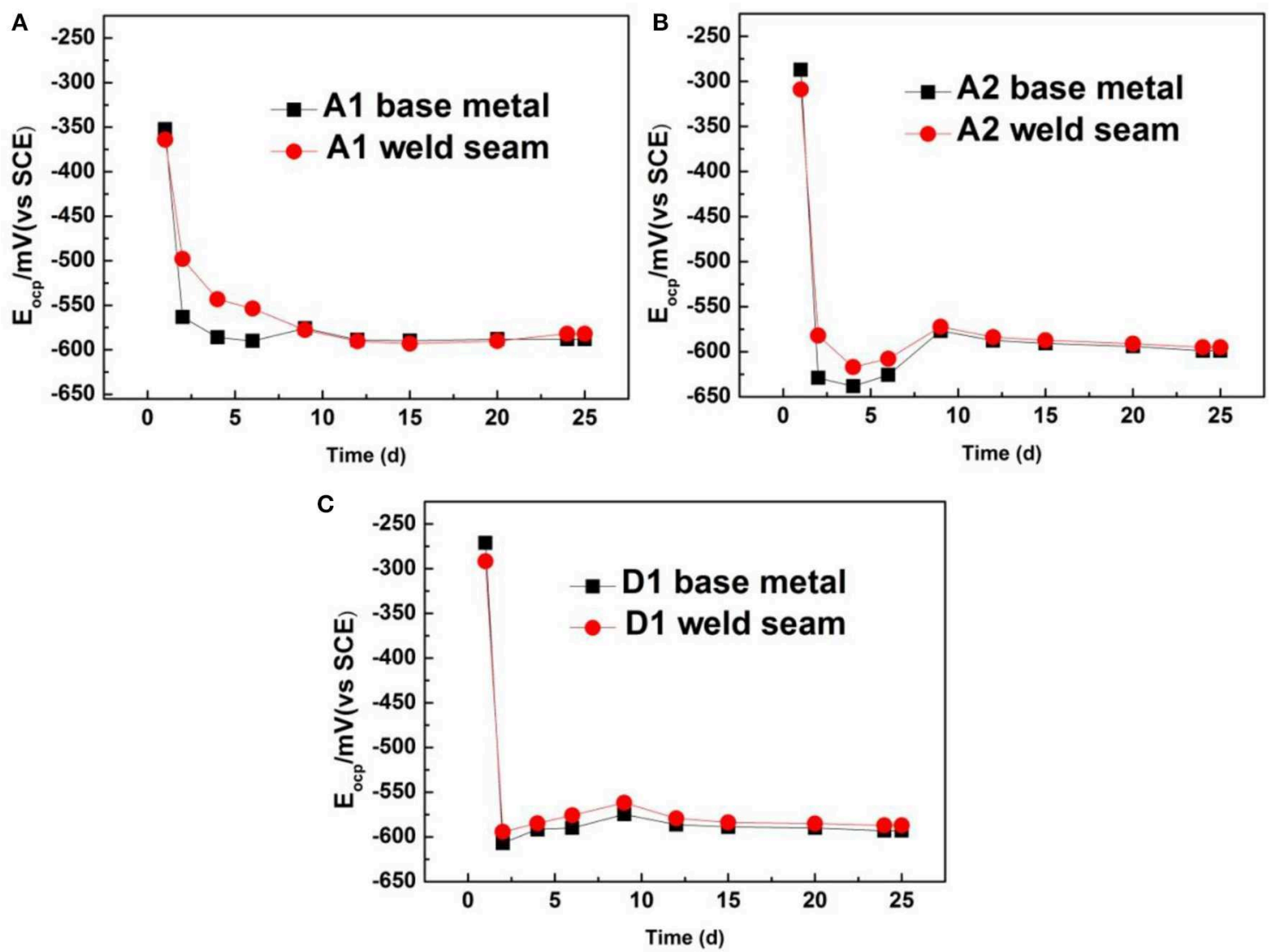

FIGURE 6 | Variation in open circuit potential with exposure time for three stainless steels: (A) A1 steel, (B) A2 steel, and (C) D1 steel.

such as proteins, nucleic acids, and lipids (Santo et al., 2011). In addition, $\mathrm{Cu}$ may kill the bacteria by oxidation process. The oxidation of $\mathrm{Cu}$-rich phase on the surface is probable, and the chemical state of $\mathrm{Cu}$ can change after exposure to the bacteria, often a reduction of $\mathrm{CuO}$ or $\mathrm{CuS}$ to metallic $\mathrm{Cu}$ (Paschoalino et al., 2008; Akhavan and Ghaderi, 2011; Liu et al., 2018b). Cu ions may compete with some metal ions for selective binding sites on proteins, leading to the loss of protein function. $\mathrm{Cu}$ ions can also inactivate proteins by damaging $\mathrm{Fe}-\mathrm{S}$ clusters in cytoplasmic enzymes needed to produce branched-chain amino acids (O'Gorman and Humphreys, 2012).

Nevertheless, it is worth mentioning here that SRB are special bacteria. It has been widely recognized that the sulfides produced by SRB also play an important role in corrosion (Yuan and Pehkonen, 2009; Yuan et al., 2013). For this reason, Yuan et al.
(2013) demonstrated that sulfides activated by SRB were much more aggressive than inorganic sulfides for 304 SS. Liu et al. (2018b) believed that the addition of $\mathrm{Cu}$ into 316L SS would not improve the resistance of SRB corrosion due to the $\mathrm{Cu}$ ions would react with sulfides produced by SRB to produce copper sulfide on the steel surface, instead of increasing corrosion of the $\mathrm{Cu}$-bearing stainless steels. However, this result is contrary to our previous work (Shi et al., 2018), which revealed that not only $\mathrm{Cu}$ ions but also ROS contributed to the SRB resistance. In addition, even though $\mathrm{Cu}$ ions are neutralized by sulfides produced by SRB and converted into copper sulfide finally, it (CuS) still exhibits adequate antimicrobial activity (Mostafa et al., 2020). Thus, although there is no direct experimental evidence to prove the mechanism of $\mathrm{Cu}$ improving the MIC resistance in stainless steels, it is reasonable to believe that A1 steel with 

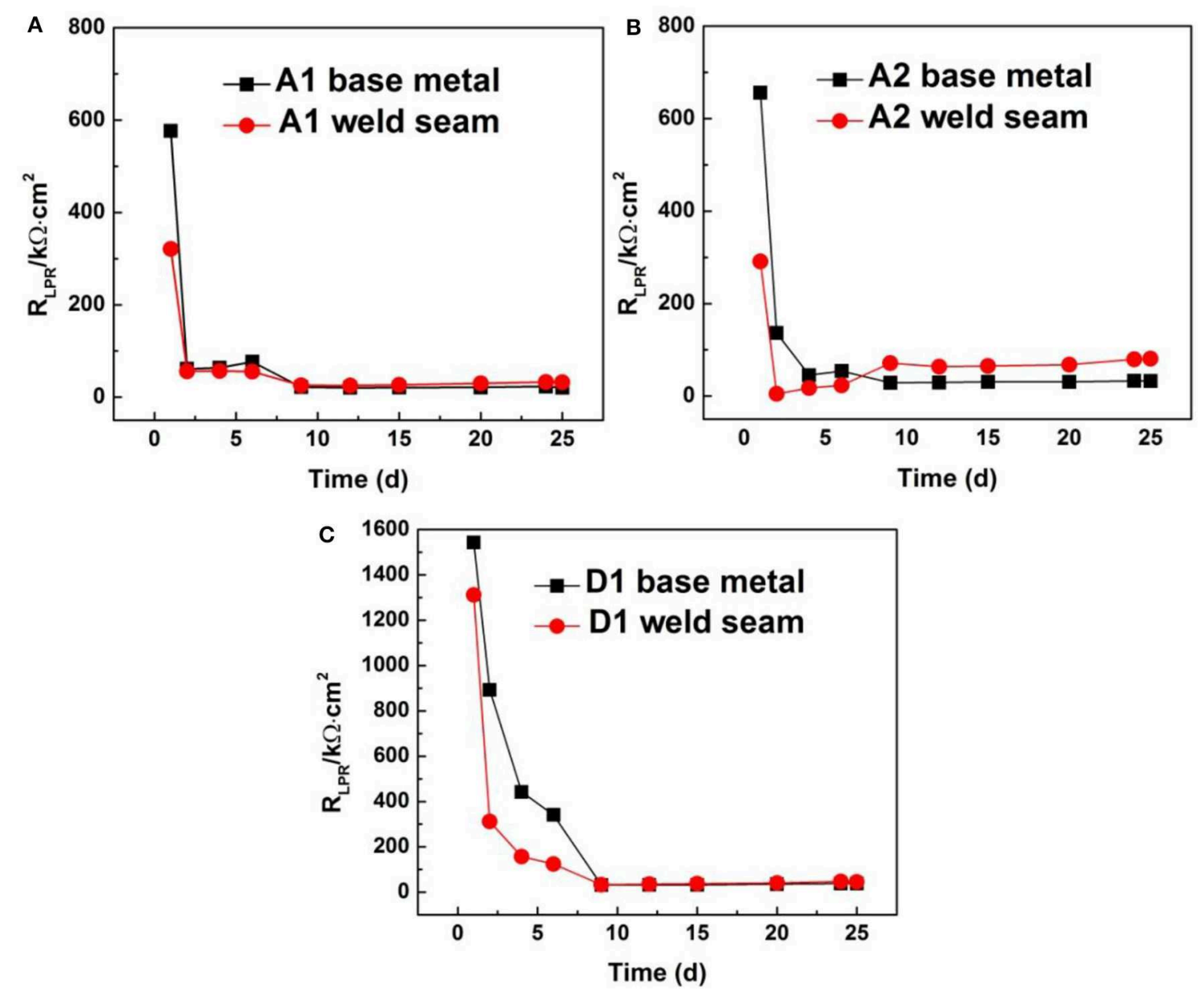

FIGURE 7 | Variation in linear polarization resistance with exposure time for three stainless steels: (A) A1 steel, (B) A2 steel, and (C) D1 steel.

higher $\mathrm{Cu}$ content would have better MIC resistance. This may be another reason that $\mathrm{A} 1$ steel showed better MIC resistance than that of A2 steel. Duplex stainless steel D1 has higher PREN value than A1 and A2 steels; however, it can be seen from the results (Table 2) that higher PREN value has no obvious effect on the resistance to MIC. On the contrary, D1 steel showed the worst resistance to MIC. Since $\mathrm{Cu}$ was not added in D1 steel, this may be the direct reason for the poor MIC resistance for the D1 steel.

\section{Open Circuit Potential}

Figure 6 shows the open circuit potential $\left(E_{\text {ocp }}\right)$ vs. exposure time data for three stainless steels (base metal and weld seam). They display a similar trend at the whole period of exposure time. The most and significant variation in $E_{\text {ocp }}$ occurred in the first 2 days. The $E_{\text {ocp }}$ values in both cases are maximum on the first day and then drop sharply on the second day. After 9 days, the $E_{\text {ocp }}$ values of three steels remain relatively stable. It is noted that the $E_{\text {ocp }}$ in the base metal is lower than that in weld seam areas during days 2-9 for both cases, and then, the difference between weld seam and base metal becomes little. As mentioned above, there may be more biofilm covered on the weld seam areas, which would make $E_{\text {ocp }}$ higher (Li et al., 2016).

\section{Linear Polarization Resistance}

Linear polarization resistance $\left(R_{\mathrm{LPR}}\right)$ is a classical electrochemical method for fast corrosion analysis that is non-destructive and can be used for study of MIC (Li et al., 2016). It is known that the $R_{\mathrm{LPR}}$ is inversely proportional to the corrosion rate, showing a high corrosion rate at low resistance. In the present study, the corrosion rate was compared indirectly by the $R_{\mathrm{LPR}}$ values. Figure 7 shows the variations in the $R_{\mathrm{LPR}}$ for three stainless steels (base metal and weld seam) as a function of exposure time. It can be found that the $R_{\mathrm{LPR}}$ values of the three steels showed a similar trend, that is, the $R_{\mathrm{LPR}}$ values of three steels behaved a sudden decrease for the first 2 days. A sharp decrease in $R_{\mathrm{LPR}}$ during the initial 2 days was correlated to the occurrence of MIC on the steel surface, which was just in the logarithmic growth phase of SRB cells (Figure 2). The reproduction of SRB and the activities of microorganisms were accounted for the sharp decrease in $R_{\mathrm{LPR}}$. Besides, the $R_{\mathrm{LPR}}$ values of the base metal were higher than that of the weld seam when SRB were just injected into the culture 
medium (the $R_{\mathrm{LPR}}$ value on first day). This is consistent with the traditional understanding that the corrosion resistance of the weld seam is lower than that of the base metal.

Another information that can be obtained from Figure 7 is that the $R_{\mathrm{LPR}}$ of the weld seam was lower than that of the base metal in the first 6 days for three stainless steels, indicating that the corrosion rate of the weld seam was higher than that of the base metal, while the $R_{\mathrm{LPR}}$ of the weld seam became similar for A1 and D1 steels after 6 days. It is not the same for A2 steel, whose $R_{\mathrm{LPR}}$ for the weld seam was higher than that of the base metal after day 6 . According to the relationship of $R_{\mathrm{LPR}}$ with corrosion rate, it can be concluded that the corrosion rate of the weld seam was higher than that of base metal in the first 6 days, then became similar after 6 days for A1 and D1 steels. Thus, its average pitting depth and the maximum pitting depth were larger than those of the base metal (Table 2). For the A2 steel, the corrosion rate of the weld seam was slower compared with that of the base metal after 6 days; however, it was much higher than that of the base metal in the first 6 days, especially on the first day. Therefore, the net result was that the corrosion rate of the weld seam was higher than that of the base metal, which in turn led to deeper pitting depth for the weld seam (Table 2).

\section{CONCLUSIONS}

The results in this study indicate how the weld seam of stainless steels could influence their resistance to MIC. The pits were found to be significantly deeper on weld seam areas than those on base metal by comparing average and maximum pit depths. The variation in $R_{\mathrm{LPR}}$ values on the base metal and weld seam showed that weld seam could promote MIC. In addition, high $\mathrm{Cu}$ content steel A1 showed the best MIC resistance followed by low $\mathrm{Cu}$ content steel $\mathrm{A} 2$, and $\mathrm{D} 1$ steel without $\mathrm{Cu}$ addition exhibited the worst resistance to MIC. Based on the analysis of different antibacterial forms and antibacterial mechanisms

\section{REFERENCES}

Akhavan, O., and Ghaderi, E. (2010). Cu and $\mathrm{CuO}$ nanoparticles immobilized by silica thin films as antibacterial materials and photocatalysts. Surf. Coat. Technol. 205, 219-223. doi: 10.1016/j.surfcoat.2010.06.036

Akhavan, O., and Ghaderi, E. (2011). Copper oxide nanoflakes as highly sensitive and fast response self-sterilizing biosensors. J. Mater. Chem. 21, 12935-12940. doi: $10.1039 / \mathrm{cljm} 11813 \mathrm{~g}$

Alabbas, F. M., Williamson, C., Bhola, S. M., Spear, J. R., Olson, D. L., Mishra, B., et al. (2013). Influence of sulfate reducing bacterial biofilm on corrosion behavior of low-alloy, high-strength steel (API-5L X80). Int. Biodeteri. Biodegr. 78, 34-42. doi: 10.1016/j.ibiod.2012.10.014

Beech, I. B. (2003). Sulfate-reducing bacteria in biofilms on metallic materials and corrosion. Microbiol. Today 30, 115-117.

Dec, W., Mosialek, M., Socha, R. P., Jaworska-Kik, M., Simka, W., and Michalska, J. (2016). The effect of sulphate-reducing bacteria biofilm on passivity and development of pitting on 2205 duplex stainless steel. Electrochim. Acta 212, 225-236. doi: 10.1016/j.electacta.2016.07.043

Dong, Y., Lekbach, Y., Li, Z., Xu, D., Abed, S. E., Koraichi, S. I., et al. (2020). Microbiologically influenced corrosion of $304 \mathrm{~L}$ stainless steel caused by an alga associated bacterium Halomonas titanicae. J. Mater. Sci. Technol. 37, 200-206. doi: 10.1016/j.jmst.2019.06.023 of $\mathrm{Cu}$, it is reasonable to speculate that $\mathrm{Cu}$ in steels should be beneficial to the MIC resistance. This study demonstrated that weld seam without filler metal addition accelerated MIC. Meanwhile, $\mathrm{Cu}$ addition in stainless steels could mitigate MIC. This result provides important information for the development of MIC resistance steels.

\section{DATA AVAILABILITY STATEMENT}

The datasets generated for this study are available on request to the corresponding author.

\section{AUTHOR CONTRIBUTIONS}

XS, MY, and WY designed the experiments and conducted the data analysis. XS and MY carried out the experiments. $\mathrm{XS}, \mathrm{KY}$, and YS contributed to the planning and coordination of the project. XS, KY, MY, and WY wrote and edited the manuscript. All authors participated in discussion about the results and the manuscript.

\section{FUNDING}

This work was financially supported by Doctoral Scientific Research Foundation of Liaoning Province (20180540083), Shenyang Science and Technology Research Funding (No. 18-013-0-53), and China Pipeline Research Organization (CPRO2018NO4).

\section{ACKNOWLEDGMENTS}

The authors would like to thank Liyang Zhu for help with MIC test and Yunpeng Zeng and Yuchen Li for SEM and CLSM observations.

George, R. P., Muraleedharan, P., Sreekumari, K. R., and Khatak, H. S. (2003). Influence of surface characteristics and microstructureon adhesion of bacterial cells onto a type 304 stainless steel. Biofouling 19, 1-8. doi: 10.1080/08927010290031017

Huttunen-Saarivirta, E., Honkanen, M., Lepistö, T., Kuokkala, V. T., Koivisto, L., and Berg, C. G. (2012). Microbiologically influenced corrosion (MIC) in stainless steel heat exchanger. Appl. Surf. Sci. 258, 6512-6526. doi: 10.1016/j.apsusc.2012.03.068

Ibars, J. R., Moreno, D. A., and Ranninger, C. (1992). MIC of stainless steels: a technical review on the influence of microstructure. Int. Biodeteri. Biodegr. 29, 343-355. doi: 10.1016/0964-8305(92)90051-O

Javaherdashti, R. (2008). Microbiologically Influenced Corrosion: An Engineering Insight. London: Springer Press.

Lekbach, Y., Li, Z., Xu, D. K., Abed, S. E., Dong, Y. Q., Liu, D., et al. (2019). Salvia officinalis extract mitigates the microbiologically influenced corrosion of 304L stainless steel by Pseudomonas aeruginosa biofilm. Bioelectrochemistry 128, 193-203. doi: 10.1016/j.bioelechem.2019.04.006

Li, F., An, M., Liu, G., and Duan, D. (2009). Effects of sulfidation of passive film in the presence of SRB on the pitting corrosion behaviors of stainless steels. Mater. Chem. Phys. 113, 971-976. doi: 10.1016/j.matchemphys.2008.08.077

Li, H. B., Zhou, E. Z., Zhang, D. W., Xu, D. K., Xia, J., Yang, C., et al. (2016). Microbiologically influnced corrosion of 2707 hyper-duplex 
stainless steel by marine Pseudomonas aeruginosa biofilm. Sci. Rep. 6:20190. doi: 10.1038/srep20190

Liu, D., Jia, R., Xu, D., Yang, H., Zhao, Y., Khan, M., et al. (2019). Biofilm inhibition and corrosion resistance of 2205-Cu duplexstainless steel against acid producing bacterium Acetobacter aceti. J. Mater. Sci. Technol.35, 2494-2502. doi: 10.1016/j.jmst.2019.05.048

Liu, H., Xu, D., Yang, K., Liu, H., and Cheng, Y. F. (2018b). Corrosion of antibacterial Cu-bearing $316 \mathrm{~L}$ stainless steels in the presence of sulfate reducing bacteria. Corros. Sci. 132, 46-55. doi: 10.1016/j.corsci.2017.12.006

Liu, H. W., Sharma, M., Wang, J. L., Cheng,. Y. F., and Liu, H. F. (2018a). Microbiologically influenced corrosion of 316L stainless steel in the presence of Chlorella vulgaris. Int. Biodeteri. Biodegr. 129, 209-216. doi: 10.1016/j.ibiod.2018.03.001

Liu, J., Jia, R., Zhou, E., Zhao, Y., Dou, W., Xu, D., et al. (2018c). Antimicrobial Cu-bearing 2205 duplex stainless steel against MIC by nitrate reducing Pseudomonas aeruginosa biofilm. Int. Biodeteri. Biodegr. 132, 132-138. doi: 10.1016/j.ibiod.2018.03.002

Liu, W. (2014). Rapid MIC attack on 2205 duplex stainless steel pipe in a yacht. Eng. Fail. Anal. 42, 109-120. doi: 10.1016/j.engfailanal.2014.04.001

Mostafa, A. M., Mwafy, E. A., and Hasanin, M. S. (2020). One-pot synthesis of nanostructured $\mathrm{CdS}, \mathrm{CuS}$, and $\mathrm{SnS}$ by pulsed laser ablation in liquid environment and their antimicrobial activity. Opt. Laser Technol. 121:105824. doi: 10.1016/j.optlastec.2019.105824

Nan, L., Cheng, J. L., and Yang, K. (2012). Antibacterial behavior of a Cubearing type 200 stainless steel. J. Mater. Sci. Technol. 28, 1067-1070. doi: 10.1016/S1005-0302(12)60174-1

O'Gorman, J., and Humphreys, H. (2012). Application of copper to prevent and control infection. Where are we now? J. Hosp. Infect. 81, 217-223. doi: 10.1016/j.jhin.2012.05.009

Paschoalino, M., Guedes, N. C., Jardim, W., Mielczarski, E., Mielczarski, J. A., Bowen, P., et al. (2008). Inactivation of $E$. coli mediated by high surface area $\mathrm{CuO}$ accelerated by light irradiation $>360 \mathrm{~nm}$. J. Photochem. Photobiol. A 199, 105-111. doi: 10.1016/j.jphotochem.2008.05.010

Ren, L., Nan, L., and Yang, K. (2011). Study of copper precipitation behavior in a Cu-bearing austenitic antibacterial stainless steel. Mater. Des. 32, 2374-2379. doi: 10.1016/j.matdes.2010.11.030

Santo, C. E., Lam, E. W., Elowsky, C. G., Quaranta, D., Domaille, D. W., Chang, C. J., et al. (2011). Bacterial killing by dry metallic copper surfaces. Appl. Environ. Microbiol. 77, 794-802. doi: 10.1128/AEM.01599-10

Shi, X. B., Xu, D. K., Yan, M. C., Yan, W., Shan, Y. Y., and Yang, K. (2017a). Study on microbiologically influenced corrosion behavior of novel $\mathrm{Cu}$-bearing pipeline steels. Acta Metall. Sin. 53, 153-162. doi: 10.11900/0412.1961.2016.00143

Shi, X. B., Yan, W., Xu, D. K., Yan, M. C., and Yang, C. G. (2018). Microbial corrosion resistance of a novel Cu-bearing pipeline steel. J. Mater. Sci. Technol. 34, 2480-2491. doi: 10.1016/j.jmst.2018.05.020

Shi, X. B., Yan, W., Yan, M. C., Wang, W., Yang, Z. G., Shan, Y. Y., et al. (2017b). Effect of $\mathrm{Cu}$ addition in pipeline steels on microstructure, mechanical properties and microbiologically influenced corrosion. Acta Metall. Sin. 30, 601-613. doi: 10.1007/s40195-017-0545-Z

Shi, X. B., Yang, C. G., Yan, W., Xu, D. K., Yan, M. C., Shan, Y. Y., et al. (2019). Microbiologically influenced corrosion of pipeline steels. J. Chin. Soc. Corros. Prot. 39, 9-17. doi: 10.11902/1005.4537.2018.147

Shu, Y., Yan, M. C., Wei, Y. H., Liu, F. C., Han, E. H., and Ke., W. (2018). Characteristics of SRB biofilm and microbial corrosion of X80 pipeline steel. Acta Metall. Sin. 54, 1408-1416. doi: 10.11900/0412.1961.2018. 00069
Sreekumari, K. R., Nandakumar, K., and Kikuchi, Y. (2001). Bacterial attachment to stainless steel welds: significance of substratum microstrucuture. Biofouling 17, 303-316. doi: 10.1080/08927010109378490

Tribollet, B. (2012). "Microbiologically influenced corrosion (MIC) in nuclear power plant systems and components," in Nuclear Corrosion Science and Engineering (Woodhead Publish. Ser. Energy), 230-261. doi: 10.1533/9780857095343.2.230

Wu, T. Q., Xu, J., Yan, M. C., Sun, C., Yu, C. K., and Ke, W. (2014). Synergistic effect of sulfate-reducing bacteria and elastic stress on corrosion of X80 steel in soil solution. Corros. Sci. 83, 38-47. doi: 10.1016/j.corsci.2014.01.017

Xia, J., Yang, C., Xu, D., Sun, D., Nan, L., Sun, Z., et al. (2015). Laboratory investigation of the microbiologically influenced corrosion (MIC) resistance of a novel Cu-bearing 2205 duplex stainless steel in the presence of an aerobic marine Pseudomonas aeruginosa biofilm. Biofouling 31, 481-492. doi: 10.1080/08927014.2015.1062089

Xu, D. K., Xia, J., Zhou, E. Z., Zhang, D. W., Li, H. B., Yang, C. G., et al. (2017). Accelerated corrosion of 2205 duplex stainless steel caused by marine aerobic Pseudomonas aeruginosa biofilm. Bioelectrochemistry 113, 1-8. doi: 10.1016/j.bioelechem.2016.08.001

Xu, D. K., Zhou, E. Z., Zhao, Y., Li, H. B., Liu, Z. Y., Zhang, D. W., et al. (2018). Enhanced resistance of 2205 Cu-bearing duplex stainless steel towards microbiologically influenced corrosion by marine aerobic Pseudomonas aeruginosa biofilms. J. Mater. Sci. Technol. 34, 1325-1336. doi: 10.1016/j.jmst.2017.11.025

Yang, K., Shi, X. B., Yan, W., Zeng, Y. P., Shan, Y. Y., and Ren, Y. (2020). Novel Cu-bearing pipeline steels: a new strategy to improve resistance to microbiologically influenced corrosion for pipeline. Acta Metall. Sin. 56, 385-399. doi: 10.11900/0412.1961.2019.00372

Yu, S., Low, Y., Zhang, D., Zhou, E., Li, Z., Du, C., et al. (2020). Microbiologically influenced corrosion of 304 stainless steel by nitrate reducing Bacillus cereus in simulated Beijing soil solution. Bioelectrochemistry 133:107477. doi: 10.1016/j.bioelechem.2020.107477

Yuan, S., Liang, B., Zhao, Y., and Pehkonen, S. O. (2013). Surface chemistry and corrosion behaviour of 304 stainless steel in simulated seawater containing inorganic sulphide and sulphate-reducing bacteria. Corros. Sci. 74, 353-366. doi: 10.1016/j.corsci.2013.04.058

Yuan, S., and Pehkonen, S. O. (2009). AFM study of microbial colonization and its deleterious effect on 304 stainless steel by Pseudomonas NCIMB 2021 and Desulfovibrio desulfuricans in simulated seawater. Corros. Sci. 51, 1372-1385. doi: 10.1016/j.corsci.2009.03.037

Zhou, E. Z., Li, H. B., Yang, C. T., Wang, J. J., Xu, D. K., Zhang, D., et al. (2018). Accelerated corrosion of 2304 duplex stainless steel by marine Pseudomonas aeruginosa biofilm. Int. Biodeteri. Biodegr. 127, 1-9. doi: 10.1016/j.ibiod.2017.11.003

Conflict of Interest: The authors declare that the research was conducted in the absence of any commercial or financial relationships that could be construed as a potential conflict of interest.

Copyright (c) 2020 Shi, Yang, Yan, Yan and Shan. This is an open-access article distributed under the terms of the Creative Commons Attribution License (CC BY). The use, distribution or reproduction in other forums is permitted, provided the original author(s) and the copyright owner(s) are credited and that the original publication in this journal is cited, in accordance with accepted academic practice. No use, distribution or reproduction is permitted which does not comply with these terms. 